\title{
THE EPC CONTRACT AND THE ENERGy LAWYER
}

\author{
ARNOLD H. OLYAN AND JOIIN K. TAYLOR
}

With conventional reserves on the decline and large scale enengy projects enticing a broader array of enerxy prodicers and transporters to consider parficipation, it is inevitable that energy lauvers will be called to advise upon and document the comtracts that will facilitate the engineering. procuremem, and consinuction (EPC) of these projects leading to commercial operation. This arficle simveys the marriage of owner and contractor that results from such contracts, beginning with preliminary issues such as controt and rolerance for risk, moving through the various contractual methods to align the parties. interests while anticipating, and responding to fluctuating circumstances, and ending with options for both owners and contractors when faced with a deteriorating relationship.
Compre renu du déclin des résenves traditionnelles et des gros proje's d envergure encouragean une gamme phis vaste de producteirs ef de transporteurs d'energic à envisager une participation. il est inévisable que les an'ocats dans le domaine de l'energie soient appelés a donner des conveils a à ridiger des comrats visant à faciliter l'ingenieric, l'approvisionnement et la construction (IAC) de ces projets avam leur exploitation commerciale. Cette article examine le mariage dil proprietaire et de l'entrepreneur qui diconle de tels contrats, en commencam par des questions préliminaires comme le controte et la rolérance d̀ l'égard dit risque, puis les diverses meihodes contractudles unilisées pour aligher les intereits des partic's rout en prévolam des circonstances fuctumanes en y ragissan pour finalemen arriver a des options pour le proprićlaire el l'entrepreneur lorsque la nelation se détériore.

\section{TABLE OF CONTENTS}

I. INTRODUCTION ............................. 540

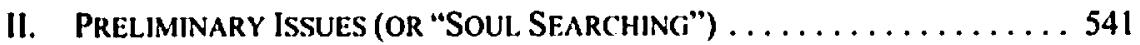

A. CompetenCy ("What ARE WE GoOd AT?") ........... 541

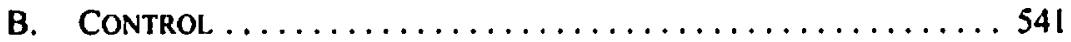

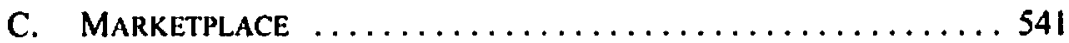

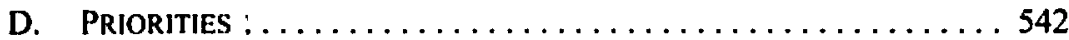

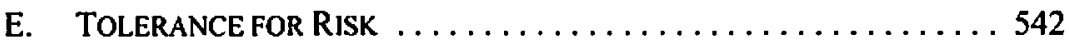

11I. ALIGNING THE PARTIES' INTERESTS
(OR "WHO IS ON MY TEAM?") $\ldots \ldots \ldots \ldots \ldots \ldots \ldots \ldots \ldots \ldots \ldots, 543$

A. BACKGROUND ............................ 543

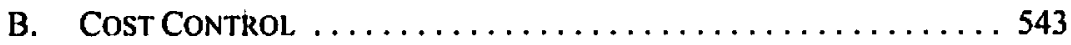

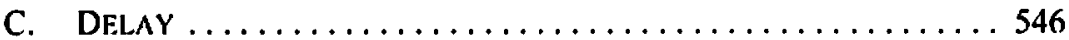

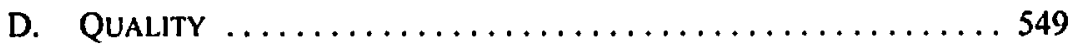

E. ANALYSIS OF LIQUIDATED DAMAGES $\ldots \ldots \ldots \ldots \ldots \ldots \ldots 51$

F. Procurement Strategy and Process $\ldots \ldots \ldots \ldots \ldots \ldots \ldots 52$

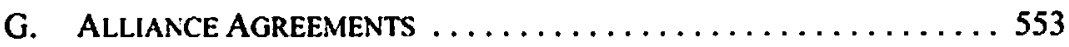

IV. Documentation (OR "Who Has the Pen?") ............. 553

V. ACKNOWLEDGEMENT OF WORK CARRIED OUT

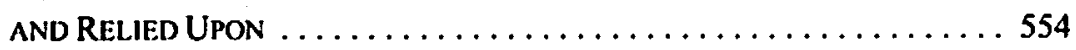

VI. The Change ORder (OR "I Thought We HAd A DEal.

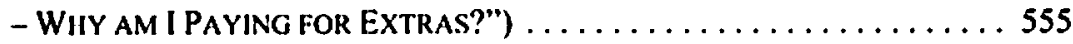

VII. POSt EXECUTION - OWNER APPROVAL AND NOTICE . ........... 557

VIII. Notice (OR "What Do You MEan You Had) No Idea?") . ....... 559 
IX. Brfach OF Contract (OR "Now the Bad News") .......... 560

X. Limitations ON LIABILITY (OR "How Bad CAN IT GeT?") . . ....... 563

XI. SOME Additional ThOughts .................... 566

A. DisPUTE RESOlUtion (OR "Do I HAVE to Go to

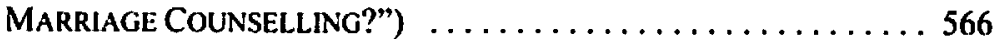

B. Prime Contractor ...................... 567

C. REgulatory Authorizations ANd PERMITTING ........ 568

D. INTELle:CTUAL PROPERTY RightS

— WHO OWNS THE "RESULT OF WORK"? . . . . . . . . . . . . . 568

XII. CONCLUSION ............................... 569

\section{INTRODUCTION}

The worst kept secret in Alberta is that the number and size of construction projects announced or being considered for the western Canadian energy sector is increasing exponentially. Initiatives include the development of massive oil sands facilities, the construction of pipelines associated with oil sands projects, and arctic gas and other energy facilities. The activities planned for the foreseeable future have stretched available staffing of regulators, engineering houses, and energy lawyers. With conventional reserves on the decline and large scale energy projects such as those noted above enticing a broader array of energy producers and transporters to consider participating in such projects, it is inevitable that energy lawyers will be engaged to advise upon and document the contracts that will facilitate the engineering, procurement, and construction of these projects leading to commercial operation.

There are a variety of agreements from which the participants in a construction project can select to provide for the various phases of engineering, procurement, and construction (EPC). Such agreements can range from a service provider carrying out a discrete type of work (i.e., engineering of a component for a project) to a service provider carrying out the vast array of the work, the latter potentially allowing an owner or other participant to focus its contractual responsibilities on one or a very small number of participants instead of the multitude of contractors, equipment suppliers, engineers, consultants, and others that will invariably be involved in the development of the project.

In the past, all forms of EPC contracts were the purview of the construction law bar. These types of agreements included design-build, engineering, equipment purchase, construction management, pure construction, EPC, and various forms of design-build-operate agreements (collectively, for this article being referred to as EPC Contracts). While energy lawyers are often called upon to draft agreements or work on projects with a long lifespan, few agreements, even complex joint venture agreements, provide for the sophisticated and integrated relationship between the parties that is required for a project EPC Contract. Indeed, the parties must recognize that by entering into an EPC Contract, they are entering into a marriage contract as much as they are entering into a commercial transaction.

This article will outline some of the more material terms and issues that the parties to EPC Contracts should consider before finalizing such agreements. The authors acknowledge that some of the subjects associated with construction (such as project insurance, builders liens, and project finance) extend beyond the scope of this article and will not be addressed in any 
detail. Other publications may be consulted for a substantive review of these topics. The authors also focus more particularly on the process and terms that a commercial lawyer will typically face when negotiating and drafting an EPC Contract. Comments will typically be biased toward identification of the owner's needs and perspective because energy lawyers wading into this realm will typically be working for owners.

For the purposes of this article, the term "contractor" will be used as a generic term that could include consultants, engineers, construction contractors. construction managers, and engineering, procurement, and construction management (EPCM) contractors who contract with owners, operators, and developers (collectively, owners) with respect to EPC Contracts.

\section{Preliminary ISSUes (OR "SOUl Searching")}

\section{A. COMPETENCY ("What ARE We GOOd AT?")}

When considering both the flavour and the specific terms of an EPC Contract, advisors to the parties should identify (and the clients themselves should previously have done some self-examination as to) their clients' strengths and weaknesses as an organization and how such strengths and weaknesses can be efficiently and effectively optimized or mitigated (as applicable). For example, an owner who intends to own and operate a pipeline may have little direct construction experience. When considering the EPC phases of the project. the owner could: (a) hire a contractor (or contractors) to deal with all aspects of the preoperations phase; (b) hire a full staff to coordinate EPC activities internally: or (c) contract for some blending of these two options. Typically, an owner with little construction experience will be more comfortable handing relative control of a project to a contractor than would an owner with more construction/construction management experience. and the owner's choice of contractual framework should reflect its comfort and competencies accordingly.

\section{B. CONTROL}

Other factors may influence and can dictate the relative degree of control the owner wishes over both the work and the contractual terms to how from it. For example, does the owner have a corporate culture that insists on control of counterpartics (and in some cases their respective subcontractors), or does it prefer to offload responsibility (and ideally risk) to third parties? The latter may indicate a preference for more of a "turnkey" arrangement.

\section{MARKeTPLACE}

It is often useful (and may assist a client in setting realistic expectations) to determine the market's appetite for various forms of agreement (and attendant risk) and what the current drivers may be that are associated with those forms of contract. For example, is the marketplace such that engineering houses are generally accepting of more risk (and presumably more reward) for certain EPC work, and does this greater appetite for risk present an opportunity for a gencrally risk-averse owner to oflload some risk through its proposed pricing arrangements and other contractual terms? Is the markelplace for particular goods or services competitive, or dominated by relatively few market leaders? 
Quite apart from how the present marketplace determines the risk aspects of an EPC Contract is how the marketplace understands the tendering process. While the scope of this article is not intended to review the law of tendering in any detail, it is fair to say that a majority of the most sophisticated players in the EPC marketplace operate with an understanding of the tendering process that is quite distinct from how the courts have prodded the participants to behave. More often than not, contractors who participate in a tendering process anticipate that the submission of bids is merely the first stage in what is often a very extended negotiation process. Once it is evident to a contractor that the owner has selected a front-running (preferred) contractor, that contractor will attempt to negotiate with the owner a variety of price, risk-allocation, and other terms that may not have been identified in an initial tender package. Owners are often complicit in such arrangements to circumvent the initial tendering regime in the hope that, with further discussions among a bidder or bidders, the price and other terms of an EPC Contract can be reworked to establish a mutually advantageous relationship. That relationship may ultimately be on different terms than were stipulated in the initial tender package. Owners unfamiliar with such tactics will often be vulnerable to a contractor who appreciates that it is the only one still at the "bargaining table" and who attempts to renegotiate terms more favourable than those that the EPC Contract originally proposed.

\section{Priorities}

It is a commonly held view that in construction projects there are three main goals that owners effectively prioritize. These priorities are: (a) maintaining budget; (b) maintaining schedule; and (c) establishing and maintaining quality. An owner's ordering of these priorities should be reflected in the owner's contracting strategy and, ultimately, in some of the specific terms of the EPC Contract. For example, if the owner's two most important goals are to stay within (capital) budget and be on time, then the contract should impose costs on, or set rewards for, the contractor if these goals are or are not achieved. In this example, and to achieve its goals, a contractor will necessarily insist on a high degree of control over its work. Lawyers must recognize the relative priority among these three goals that their clients may formally or informally establish so that the nature and terms of the applicable EPC Contract properly reflect those relative goals, and the trade-offs inherent in such prioritization.

\section{E. TOLERANCE, FOR RISK}

The most efficient and effective EPC Contract will recognize that the parties' allocation of risk and reward must be a proper reflection of their respective appetites for risk and quests for reward. Parties often do not spend sufficient time identifying their respective interests in this regard and may not adequately articulate their interests to their own counsel, among business units within one organization, or to the counterparty. As a result, the parties may be well into the process of negotiation when they discover that their respective philosophies as to risk allocation are leading to unnecessary confusion and tension that is not conducive to finalizing an agreement.

Given the long-term and integrated relationship that invariably results from the execution of an EPC Contract, it is essential that the parties understand their own goals in this regard and properly coordinate their activities under the EPC Contract to reflect this. The lion's 
share of risk should be borne by the party most able and willing to manage that risk, and such party should be rewarded in a commercially reasonable fashion. By improperly allocating risk, the relationship between parties will be marred by resentment, much like a troubled marriage. Parties may then manipulate the systems that have been established in the contract (such as change orders, reporting systems, and approval mechanisms) in an effort to redistribute the risk and reward and to "claw back" rights and obligations that may not have been properly articulated at first instance.

\section{Aligning the. PARTIES' Interests (OR “WhO IS ON MY TEAM?")}

\section{A. BACKGROUND}

In a typical agreement for goods or services, the parties agree on the nature of the item to be delivered (size, quantity, technical specifications, and the like), the timing of such delivery, and what the implications will be of a failure to deliver in the manner prescribed in the contract. As a good or service becomes more specialized and tailored to the purchaser's specific needs, the causes and implications of a supplier's breach of contract are more problematic and difficult to assess. This is particularly so in respect of EPC Contracts because they often entail the participation of numerous contractors, subcontractors, and other participants whose views may vary as to their level of responsibility for a failure of a contractor to satisfy its contractual commitments. These differing perspectives invariably drive a participant's view of how to rectify a problem. A key to participation in a project is to establish a contractual framework among parties that will minimize the finger-pointing that can result in added delay and cost to the party who has accepted responsibility for performance.

To overcome the typical and often unproductive adversarial nature of contracts, owners and contractors have developed various techniques to align the parties' interests. While the partics would rarely be characterized as "partners" in a formal sense, they do attempt to recognize the interdependence between them and often provide for contractual terms to encourage behaviour that will increase the probability of satisfying the owner's goals of maintaining budget, ensuring a certain level of quality, and completing the project within the expected schedule.

Some of the tools that have been incorporated into EPC Contracts are identified below. They are by no means exhaustive.

\section{B. Cost CoNTrol.}

\section{PRICING}

EPC Contracts must contain one or more costing/payment scheme. The scheme chosen should reflect the parties' views on whether the owner or the contractor should accept the cost risk of a particular project (or portion thereof). In descending magnitude of price risk to the contractor (the reciprocal being true for the owner) the following costing arrangements can be instituted: 

(i) lump sum;
(ii) unit price;
(iii) target price; and
(iv) reimbursable/cost-plus.

The foregoing categories are merely general descriptions of the common options available to parties and it should be understood that each of these four only generally characterize the compensation arrangements between the parties. Indeed, some of these "labels" have been attributed to contracts that in fact place little risk on the party to whom the costing strategy is generally viewed as taking on significant cost risk! The reason for this is that these pricing "Icrms" are often misconstrued or misapplied. Typically, the misuse of such terms is a result of parties diluting the initially proposed compensation arrangements through the negotiation process, but failing to recharacterize the revised compensation terminology. For example, an owner may intend to contract on a "lump sum" basis but, as a result of contractor counter proposals, the owner recognizes that the only "lump sum" pricing that will be offered is at a significantly higher price than that for which the owner budgeted. The owner may continue to characterize its contract as "lump sum" even though many of the contract costs are in fact priced on some other (presumably cheaper), variable basis.

\section{a. Lump Sum Pricing}

This pricing arrangement suggests that the owner will pay a set amount for all goods and services to be delivered by the contractor, regardless of the contractor's out-of-pocket costs. This framework provides the contractor with the greatest risk of future cost deviation and imposes a higher obligation on the contractor to deliver its work at a pre-determined price. Theortically, this price is "locked in" and any deviation in the inlerent costs associated with delivery of the work will be at the contractor's risk (or reward, as applicable).

\section{b. Unit Price}

Under this pricing arrangement, various elements in a basket of work are identified as "units" and are priced accordingly on a per unit basis. Such a quote is most often associated with pipeline (or other linear) construction. It should be reflective of a basket of lump sum prices with which an experienced contractor often has a higher degree of comfort. It places significant cost risk on the contractor, who is committing to deliver the particular quantum of units at the pre-determined price per unit.

\section{c. Target Price}

This somewhat more flexible pricing arrangement puts the shared burden of cost control on both the contractor and the owner, but not necessarily in equal measure. The parties must establish a bascline or budgeted value for the work to be carried out, and the parties agree that the costs in excess of the budgeted amount will be shared in some proportion as set out in the EPC Contract. If the actual costs are ultimately lower than the baseline, then the parties will similarly share in the savings in accordance with a pre-determined ratio. This format should align the parties" interests to a significant degree and encourage both parties to keep costs down. 


\section{d. Reimbursable/"Cost-Plus"}

This costing arrangement, which is also characterized and known as "time and materials," typically provides that the contractor will work an hourly rate and will be reimbursed for all of its out-of-pocket expenses. This arrangement is similar to that of a law firm or accounting firm that bills out its time and expenses. The owner bears the greatest price risk within this framework. One might agree that the contractor may not be particularly motivated to identify costs savings that might result in a less expensive project because the contractor is simply "billing their time." However, the contractor will generally be well situated to supplement incomplete or low quality work and identify longer term goals such as ensuring quality work and lower operating costs because the contractor will not bear any of the financial risk associated with changes to the initially proposed work. This regime is particularly useful when a scope of work is less than fully developed at the time the contractor is retained to do the work, or when the contractor has been engaged to develop that scope of work.

To use a simple analogy, the lump sum compensation arrangements would be analogous to "locking in" a mortgage over a particular period of time, thereby providing the owner with the greatest certainty as to the payments required of the owner to satisfy its obligations. The reimbursable framework would be more akin to the selection of a mortgage with floating rates, exposing the owner to the risk that the marketplace, and other perhaps previously unconsidered factors, could significantly upset the owner's budgeted costs.

One benefit of the target price regime is that, if properly structured, it should encourage the parties to work cooptratively to identify immediate cost savings. Depending on target price arrangements and the scope of work structure, the pricing regime in EPC Contracts can encourage the parties to develop a more efficient operating plant (resulting in cost savings to be shared by both parties) or other desirable outcomes.

A target price regime and a lump sum regime will, by their nature, encourage the contractor to ensure a clearly defined scope of work because the contractor will be unwilling to accept price risk. By establishing a clear scope as well as a cosv/profit-sharing regime, parties will be better positioned to realize savings. Focusing the parties' energies on establishing a proper scope of work should result in overall cost savings, regardless of the party achieving financial reward under the terms of the EPC Contract.

\section{AUdit Provisions}

Owners will be anxious to ensure that the amounts included in a project's costs are being properly accounted for so that amounts paid by the owner are not the result of "double counting" or mischaracterized entries for the inappropriate benefit of the contractor. Since a contractor will typically be incurring many of the initial project costs, contractors may have the opportunity, if not the intention, to manipulate amounts payable by the owner. The use of audit provisions to oversee linancial matters is particularly important when target price and cost reimbursable pricing arrangements are operative. With these pricing arrangements. the owner should ensure that its audit provisions are sufficiently robust and its audit team is sufficiently familiar with the I:PC Contract so that audit systems and expectations can properly identify cost and quality discrepancies before patterns become entrenched and decisions are made that cannot easily be reconciled or rectified. 


\section{USE OF Progress PAYMENTS}

Contractors will prefer to schedule payments of their fees so that the compensation they receive from owners is well in excess of and in advance of their own out-of-pocket expenses (including payments to subcontractors). An owner that understands the contractor's cost structure and subcontractor payment schedule will conversely wish to minimize fees paid to the contractor that are effectively financing the contractor's operations. The parties will need to establish a framework to overcome this tension. Although it would be more efficient to have the party with the lowest cost of capital financing purchases, it is more often the case that the party with the greatest bargaining power and information at a given point in time will establish a payment schedule that best suits its needs.

Owners can provide a measure of control by insisting that a contractor's invoices for work performed correspond with the contractor achieving various contractual milestones. By way of a simplistic example, an owner may be unhappy to receive a contractor's invoice on Day I for the purchase of a large piece of equipment that is not ordered until Day 30 and in respect of which payment is not required until Day 60. The owner may wish to establish a framework for "milestone payments" whereby the contractor may only invoice the owner on Day 60. Alternatively, if there is a 30-day lag between the contractor's invoice date and the date on which payment from the owner is due, then the contractor's invoice to the owner for the amount should perhaps only be issued on Day 30 . Such a cash neutral framework minimizes the cost of financing purchases and ensures that the contractor (or the contractor's supplicr of goods or services) is not using the payment schedule as a profit centre.

A contractor might prefer a payment schedule based on monthly or quarterly instalments paid over the life of the contract. Owners should be aware that a contractor's costs are irregular over the life of an EPC Contract. Initially, a contractor may face significant mobilization expenses and may thereafter experience wide monthly fluctuations in costs incurred. For example, orders for large pieces of equipment or a construction workforce mobilization to a construction site may drive up one-time costs significantly. A smooth payment schedule over, for example, a two-year period, may not be a realistic reflection of the contractor's actual expenses. It may, however, be that the owner would prefer a more simple, predictable, and even series of payments over the life of a contract regardless of the connection between the amounts paid by the owner and the costs incurred by the contractor to satisfy the EPC Contract.

\section{DeIAY}

\section{Milestone Payments}

An owner can attempt to coordinate its payment of costs with work progress via a milestone payment schedule. Through the use of milestone payments, an owner can more effectively encourage a contractor to stay on schedule by providing in the EPC Contract that payments otherwise then payable will be suspended until particular milestones are satisfied. The contractor could find itself in the troubling situation of having to pay its staff and suppliers without the benefit of receipt of otherwise regular payments from the owner. While the owner would not intend to bankrupt the applicable contractor by the use of such a strategy, aligning the contractor's interests (in receiving regular and sufficient payment to 
cover its costs and earn profit) with the owner's needs (to maintain schedule) can be an effective tool to keep a contractor focused on matters of mutual concern.

In varying degrees, any EPC Contract will place significant responsibility on the contractor to coordinate availability of personnel, receipt of products, and delivery of documents in an efficient and precise fashion. Owners and contractors are best served when this coordination function is initiated immediately upon execution of the EPC Contract and is continued throughout the work. Specifically, contractors and owners should regularly meet to discuss: (i) the attainment and satisfaction of certain milestones; (ii) delays that may have become evident with certain suppliers that may be felt in more than one portion of the project: and (iii) the status of initial engineering and design documents, the delay of which could ripple through the procurement and construction phases of a project.

Milestones will be project-specific and parties should identify their own particular needs and develop systematic milestones that satisfy these needs. If each party can accurately identify bottlenecks within their own organization that may be the cause of delay and, carly on in the process, identify those aspects of the other party's organization that are causing delay, then overall project delay can be minimized. Document registers, formal reporting systems, and communication representatives can ensure that all material information is being effectively provided to the individual or individuals able to address inquiries, provide requisite feedback, or attend to filings as quickly as possible.

\section{BONUS FOR EARLY COMPIETION}

In a competitive marketplace, contractors may request rewards for carly completion of their activities. The value and trigger lor such a "bonus" will be the subject of negotiation.

While carly completion may seem like a desirable goal, early completion may disrupt the activities of other contractors associated with the project. For example, if a contractor's work includes the delivery of all materials and construction equipment to the site and the contractor delivers such materials and construction equipment to the site months prior to the site being ready for their arrival, the owner may be faced with unexpected storage charges and maintenance costs. While costs could be mitigated by lixed price management, an early delivery of equipment or materials may actually be a significant impediment to efficiency on the site. particularly where lay-down yards or on-site access is limited. This may be particularly problematic for urban construction projects or for remote construction sites with seasonal access constraints. Partics should therefore place parameters on a bonus such that it encourages delivery that is both timely and beneficial.

Some owners are resentful of the suggestion that a contractor should be rewarded for early completion of work for which the contractor is already being paid. However, the marketplace may dictate that contractors be motivated to stay on schedule. particularly if other projects the contractor may be associated with will impose liquidated damages or provide early completion bonuses, thereby encouraging a contractor to dispense with one owner's project in favour of another. As well, in an overheated "contractors' market," owners may be faced with the need to offer early completion bonuses in exchange for the contractor agreeing to liquidated damages provisions for late completion. 


\section{CoOrdinated Labour Strategy}

In Alberta, provincial law permits the establishment of a coordinated labour strategy whereby contractors are requested to accept certain project-wide labour agreements. Such agreements attempt to harmonize labour rates and work schedules and help minimize work disruption as a result of building trade or other disputes at the construction site. Division 8 of the Alberta Labour Relations Code' essentially provides for a legislative regime that supersedes current labour agreements with the various building trades. While the scope of this article does not warrant a thorough discussion of the matter, an owner's attempt to organize the allocation of work and the coordination of workers based on their union or other affiliations is a transparent attempt to minimize onsite disputes among workers, thereby increasing the likelihood of the project being developed and completed on schedule.

\section{Directing Measures}

It is often the case that an owner will recognize that it is too important for the timing of a construction project to allow disputes between the owner and the contractor regarding price for a particular "extra" or "change" to hold up the actual required work. Particularly in the case of a requested change in scope by an owner that is intended to address an identifiable shortcoming in the initial scope of work, the owner will not want the contractor to delay significantly the current/upcoming work as a result of the change in scope of work while the parties haggle over pricing or other concerns. Conversely, a contractor will be reluctant to make a quick assessment of the additional costs associated with the proposed change in scope if the contractor is expected to accept the risk associated with inaccurately quoting the prevailing market prices for labour, equipment, materials, or other inputs that then may be subject to market fluctuations. In consequence, the contractor may incorporate a risk premium or premium associated with the inconvenience of the change in scope of work when it proposes a price for the particular change order. Any of these possibilities may result in disputes, but neither party will want the contractor's efforts to be unnecessarily distracted by pricing concerns when the parties should be more focused on the work to be carried out and the schedule to be maintained. Consequently, the owner will often insist on the right to direct a contractor to carry out certain work under a change order regardless of whether the pricing for the change order has been settled. At a minimum, the owner will insist that any other work subject to the change order continue as scheduled while the change order is being priced.

The directive measures noted below in Part IX, including those that may be imposed by the owner in the event that the contractor is behind schedule, will often provide that the owner may, upon notice, direct the contractor to carry out certain work in order to address a proposed change order or rectify the owner's then current concerns regarding the contractor's ability to maintain its schedule. While such directive measures may seem particulariy owner-biased, they can be qualified to allow the contractor a significant amount of notice and may provide for caps on liability, thereby acknowledging that the contractor may be constrained financially, logistically, or by external forces such as labour and materials. Such terms do force the contractor to remain sufficiently flexible so as to address 
an owner's needs on a relatively prompt basis and in a manner that, in other commercial circumstances, might be considered unreasonable or unacceptably onerous.

\section{Quality}

\section{APPROVAL OF SUBCONTRACTORS}

EPC Contracts often require contractors to disclose in advance those subcontractors or sub-suppliers that may supply goods or services on behalf of the contractor. Such provisions can assist both parties to an EPC Contract. The owner's approval in advance of at least the major subcontractors/sub-suppliers may allow the owner to voice any reservations it may have regarding the quality of work or the reliability of supply. Similarly, if a contractor learns early into the EPC Contract that a proposed subcontractor is unacceptable to the owner, then the potential inconvenience to the contractor (and cost and schedule implications) can be avoided, or at least minimized. Owners concerned about poor quality resulting from the selection of subcontractors/sub-suppliers should also be considered against the contractor's predisposition to favour the subcontractor with the lowest cost, particularly in a lump sum context. As with most goods and services, the lowest cost provider may not be the highest quality provider.

\section{COMMON SITE SERVICES}

Owners of larger projects have recently begun identifying the benefits of the owner making available to contractors the services and supplies of other contractors available to provide goods or services at or near the construction site. Such common services provide contractors with the opportunity to source materials, equipment, and expertise from onsite providers, often on a short-term basis, and directly from the provider with little or no involvement from the owners. Pricing and other contractual terms would be pre-arranged between the third-party provider and the owner. The benefit to the owner is that they will be aware of the likely providers and standardization of certain essential goods or services at the site.

The contractual basis for the relationship among a common services provider, the owner, and any particular contractor can be problematic because the owner may not necessarily be a party to the actual supply or service agreement between the contractor and the common services provider. It would be awkward for the owner to manage the quality or delivery obligations between the contractor and the common services provider. The owner may benefit from such an (two-party) agreement by avoiding responsibility for any delay or default for which the common service provider may be responsible. Contractors may be reluctant to accept responsibility for such site services providers, particularly if they have been hand-picked or insisted upon by the owner, unless the owner back-stops availability, price, warranty, or other terms to which the common services provider has committed.

\section{ASSIGNMENT OF OWNER AGREEMENTS}

Depending on the sufficiency of initial engineering and design carried out by an owner, an owner may wish to mitigate risk by pre-purchasing "long lead components" or services in advance of entering into more central EPC Contracts for the project. For example, 
significant pieces of machinery may be readily identifiable and ordered early on in the procurement process for early delivery to and installation at the construction site. Such purchases may be procured by the owner directly, thereby allowing the owner to ensure that the counterparty is a quality supplier and able to satisfy the delivery, quality, and pricing terms of an initial purchase agreement. Once the EPC Contract is executed, the owner would assign the purchase agreement to the contractor, thereby ensuring that the long lead purchase agreement is being managed by the contractor as the person best able to manage the quality, delivery, and other requirements under the applicable purchase agreement. Therefore, the purchase agreement should make reference to possible assignment to an EPC contractor in the future. Well in advance of executing the EPC Contract, it would be incumbent on the owner to obtain vendor consent to assignment of the long lead agreement so that the assignment of that agreement to the EPC contractor would be seamless, understood by all three parties, and priced into the EPC Contract. Any security that the owner obtains initially from the long lead supplier should be assignable to the EPC contractor.

\section{Site ACTIVITIES}

An efficiently organized construction site may increase the quality level of the end product. If distractions and delays resulting from logistical impediments persist, the contractor's on-site workers may be less motivated to ensure the quality of their work. Such concerns can be exacerbated by the tensions that may exist between union, non-union, and alternate union personnel carrying on activities at the same construction site (an "open site"). If owners and their contractors can develop a project site work agreement under applicable labour legislation, there should be greater likelihood that the end product will be delivered on time and in compliance with applicable specifications. While the scope of this article does not permit a lengthy discussion on the matter, an order pursuant to Division 8 of the Labour Relations Code ${ }^{2}$ allows owners initiating major construction work to garner legislated protection under negotiated labour agreements so as to minimize on-site labour disruptions. Such agreements are intended to balance labour union interest in maintaining pay and benefits for their workers at construction sites, with an allowance for competition among non-union and alternate union workers in a coordinated and fair fashion. Accelerated construction activity in Northern Alberta may well test these Division 8 orders and other coordinated worksite arrangements in the future.

\section{BONUS COMPENSATION}

An owner whose primary or secondary goal is work quality may be willing to compensate the contractor for satisfying certain safety, durability, reliability, or efficiency targets. In recent years, the construction industry has become increasingly sensitized in respect of safety, and an EPC Contract linking a successful safety record to a compensation scheme will offer further incentives to contractors (and owners) to ensure the highest safety standards. Similarly, it is now increasingly common for bonuses to be paid to contractors (or their staff) who remain engaged on the same project to its conclusion, instead of being enticed to join another project (or contractor) prior to completion of the first initiative. 


\section{E. ANALYSIS OF LIQUIDATED DaMages}

Owners may link reliability or efficiency of a facility or meeting the completion date with liquidated damages provisions. Ideally, liquidated damages would be triggered upon the occurrence or, more accurately, the non-realization of, quantifiable criteria. In a robust construction environment, contractors may request that liquidated damages provisions be matched with bonuses to further align the parties' interests and satisfy collective goals. As with bonus arrangements, liquidated damages for quality shortfalls are most common and particularly useful when design, engincering, procurement, and construction are linked quite closely so that one contractor can identify and manage all aspects of a facility"s ability to meet the initial design criteria.

An owner's ability to maintain a viable liquidated damages provision in an EPC Contract that does not cover the full scope of the construction work is often jeopardized by its other site contractors' activities. For example. if the owner has established separate relationships with an EPCM contractor (performing the role of construction manager) and a construction contractor, it is inevitable that any delays in the construction phase of the project will result in each of the parties blaming or linking the delay to the other contractor or the owner's activities/delays, as applicable. Such finger-pointing can also arise between a contractor primarily responsible for design and other contractors responsible for construction or construction management. If an owner wishes to ensure that its EPC contractors are responsible for the results of their respective work and that liquidated damages provisions. whether in respect of timing, performance, or other goals are taken seriously, proposed liquidated damages should be thoroughly mapped out in advance of contract negotiations so that the owner's desired matrix of risk and responsibility are properly reflected in the liquidated damage provisions that are negotiated.

Liquidated damages provisions in an EPC Contract should allow an owner to recoup costs associated with a contractor's delay in delivering its work, shortfalls in performance of the facility being prepared, or other obligations under the contract to which the parties have agreed. The authors are also seeing liquidated damages extended to "charges" for certain changes to staff initially included by a contractor on a "project team" for a particular project. An owner may be particularly concerned about losing key individuals on a project team and may attempt to quantify the administrative or other costs associated with the contractor changing out personnel by imposing a charge that is essentially a form of liquidated damages.

When liquidated damages are proposed for inclusion in an EPC Contract, the general legal principles associated therewith will govern. The amount of liquidated damages to be awarded is to be a genuine pre-estimate of damages agreed to in advance by the parties."

On occasion, parties may be willing to stipulate an amount (or formula) to approximate the anticipated and logically flowing losses in the event of the particular breach of contract triggering liquidated damages. The formula need not be the eventual result of the costs or losses incurred as a result of the breach of contract, but should be a reasonable approximation 
of the anticipated losses. In a complicated construction project, contractors will be wary of providing liquidated damages to an owner whose project is delayed or deficient for reasons other than those attributable to the specific contractor; however, the quantum calculation under the liquidated damages provisions could be discounted to account for the probabilities associated with the critical path of the project being delayed by other contractors, or by a facility performance shortfall resulting from the design or construction deficiencies of others.

When developing a formula to calculate liquidated damages, consideration should also be given to staggering the significance of the liquidated damages to be awarded such that delays of a relatively minor nature, that might be recouped with little cost, be valued at a relatively low amount. Once delays or performance shortfalls of a significant nature are recognized, the quantum of liquidated damages (ideally calculated on a daily or weekly basis) could be increased accordingly to reflect the more significant nature of the damages that are being incurred. While such a formula might be challenged as a "penalty" in a financing arena, it appears more likely that in an EPC Contract context the increased daily or weekly costs could reflect the actual losses to an owner in those circumstances. Liquated damages claims are often capped in EPC Contracts so as to limit the contractors' exposure to a not insignificant, but reasonable amount.

Liability for consequential loss is often limited in an EPC Contract. As a result, it may be necessary to exclude liquidated damages provisions from the typical limitations on the award of consequential losses. This is done so that a party cannot rely on the potential inconsistency between the general claim that parties are not entitled to consequential losses and the entitlement of an owner to recover damages associated with delay or performance shortfalls, which likely include elements of lost profit, lost opportunity, and the like.

\section{F. Procurfment Strategy and Prochss}

A party's procurement strategy should be identified and articulated before that party enters into negotiations with a counterparty. Without a clear strategic understanding, the party's position on certain commercial, risk, and administrative matters and the party's ability to negotiate a contract that will satisfy the party's goals will be significantly compromised. Internal harmonization among a party's negotiators must be well coordinated on large projects to allow that party to recognize and seize commercial opportunities.

Without proper coordination between the business units of a party (often the owner), opportunities to garner economies of scale may be lost. For example, batches of certain materials or services that a contractor or supplier may be providing to a project could, and should, be grouped in larger orders, on preferential pricing arrangements, and with uniform terms and conditions. More troublesome from a commercial and technical standpoint would be if a raw materials provider or provider of services has contracted with an owner on the basis of a previous agreement and the owner, as a result of its own internal miscommunication, has not identilied how the latest order may require unique terms or specifications. In such a situation, the owner's position will be compromised at best, and unenforceable at worst. Internal communication among procurement specialists, engineers, and others within an owner's organization should at a minimum extend to contracting strategy, standardization of terms of agreement, and specification development with the EPC contracting strategy in mind. 


\section{G. Al.l.IANCE Agrhemints}

Mega-projects provide ample opportunity for contractors and owners to enter into "alliance agreements." Such agreements are intended to align the interests of owners and all material EPC contractors on the project to the greatest degree possible, thereby ensuring that all contractors and owners benefit from or pay for the successes and shortcomings of the work being carried out on a project. The terms of such agreements can be as complicated or as simple as the parties may consider appropriate, but a "line of sight" between risk/reward and project outcome is essential.

An alliance agreement might relate primarily to the costs of certain portions of a project that are often delineated among contractors based on their respective scopes of work. Delays in project completion and quality shortfalls might also be included in the risk/reward sharing and payment formulae developed by the parties to the alliance agreements.

Alliance agreements will often require management committee oversight and intricate reporting systems. Coordination of the project's change order management system among contractors and owners is also required. This ensures that all partics are aware of events arising on other portions of the project in respect of which they have less familiarity, or in respect of which their work is dependent. The audit provisions must be thoroughly scrutinized so that parties are aware of the information they are required to provide to the management group and that they are entitled to obtain from other parties. Parties to such agreements must become comfortable with the notion that some of their ideas, documents, and efforts will be shared with a broad array of participants, some of whom may be traditional competitors for other projects. Such requirements are intended to facilitate innovation and efficiency, thereby benefiting the project and, as a result, the parties.

The benefit to owners of such agreements is that their interests are thoroughly aligned with the contractors and that risk is spread among the parties best able to manage it. A disadvantage to owners participating in such agreements may be that they forego a degree of control over the project. Particularly where the scope of the project is poorly defined, the various parties are less likely to identify properly the "weak link" in any particular cost overrun, delay, or quality shortfall scenario precisely because no party has taken ownership of that "weak link."

\section{Documeniation (OR "Who Has the Pen?")}

Once the drafter has a general sense of the principles that should guide the EPC Contract, a cogent document must be prepared. Unlike most other contracts, the contents of an EPC Contract for a large project may well be a compilation of documents developed by many (often hundreds of) individuals from different disciplines. This may include engineers, safety experts, lawyers, accountants, procurement specialists, and risk managers. Because the forms of agreement are developed by such disparate groups, it leads to the unsettling circumstance that no one particular person or group of individuals will have reviewed the entire agreement. By necessity, individuals from one organization must rely on the competence and diligence of others within the organization. This is to ensure that, for example, specifications contained in the scope of work document and technical aspects of the EPC Contract properly conform with, among other things, certain terms and conditions, the commercial basis for the 
agreement, the insurance requirements, the health and safety requirements, the site activity plan requirements, and similar, site-wide provisions.

Certain industry associations such as the Construction Owners Association of Alberta and the Canadian Construction Association have developed forms of EPC Contracts that can be a helpful starting place for dralters. ${ }^{4}$ Caution must be exercised, however, before using such precedents without reviewing them against the partics' views and needs, as summarized above in Part II.

The person or group within a party's organization who is responsible for coordinating the preparation, redraft, internal circulation for comment, and "lock-down" of EPC schedules, exhibits, and terms may find itself at odds with some or all of the sub-groups within the organization due to conflicting goals and agendas. These conflicts may be as a result of differing time, budget, or quality priorities. Lawyers in some cases will not have the authority to determine various commercial, risk-related, or financial terms being considered for inclusion in an EPC Contract. Internal consensus building will therefore be vital long before external negotiations with a counterparty begin.

Notwithstanding these logistical roadblocks, it is essential that the lawyer's role not be restricted to the review or preparation of the terms and conditions of the EPC Contract. Often the drafters of the scope of work, compensation, change order management, and document control provisions of the EPC Contract are unfamiliar with the terms and conditions of other provisions of the EPC Contract. The inconsistencies or repetition that may arise from different individuals drafting in isolation can be minimized if the lawyer is provided sufficient opportunity to review all aspects of the EPC Contract well in advance of the lendering or negotiation process. This principle applies equally to any review of bid packages that are often developed without the involvement of legal personnel. It is unfortunate and embarrassing, as well as potentially costly to the owner, when bid proposal materials are inconsistent with the proposed form of EPC Contract included in a bid package. Anecdotal evidence suggests that an EPC Contract with three force majeure provisions can be uncovered from the most sophisticated of owners! While such inconsistencies may be viewed as opportunities by our barrister friends, owners and contractors alike would prefer to avoid disputes of this nature at all costs.

\section{ACKNOWI.EGLMENI OF WORK CARRIED OU'T ANID RELIED UPON}

EPC Contracts often reflect a general statement as to the nature of each party's preexecution review of all or certain portions of the proposed form of EPC Contract. A contractor may not be expected to understand the technical basis for, or to have reviewed all of the aspects of, the EPC Contract that may have been developed, particularly if certain schedules or other aspects of the EPC Contract have not been presented to the contractor prior to exccution of the EPC Contract. It is sometimes the case that details of some portions

See Construclion Owners Association ol Alberta (COAA), "Model LPC Contract Form," online: COAA <www.coaa.ab.ca/BE.STPRACIICES/Contracts/ModelEPCConlractForm/abid/99/Default.aspx>and Canadian Construction Association (CCA), "CCA Electronic Documents," online: $\mathrm{CCA}<w w w . c e a-$ aec.com/documents/electronic/download.htmls. 
of the EPC Contract are not made available to the contractor until after the parties have entered into the EPC Contract. The EPC Contract might limit the contractor's site activities in the expectation that the contractor will rely on the results of certain engineering studies carried out by a third party, or rely on the pricing of certain inputs for the account of either the owner or the contractor. Non-lawyers may not appreciate the need for a complete EPC Contract, with all relevant schedules, being available on the date of contract execution. In these circumstances, the change order and other mechanisms in the EPC Contract should allow for the introduction, review, and agreement of the parties to specilic additional elements that are to be included in the EPC Contract after the date of execution.

A change order mechanism is discussed below, but in addition to such a mechanism, the parties should acknowledge their respective understanding regarding: (a) who has carried out a review of any portion of the other party's work; (b) who has reviewed and confirmed the conclusions or determinations arising out of such work; and (c) who is merely relying on the other person's work and building on such work as the basis for subsequent work. For example, if an owner has carried out certain geotechnical surveys, either by itself or through an agent, it may be reasonable in some circumstances for the owner to accept responsibility for the analysis carried out by the applicable surveyor. If the owner (presumably with the consent of the applicable surveyor) makes such a survey available to prospective contractors, then the owner must determine to what extent it is comfortable having the contractor rely on such information as the basis for submitting a bid on subsequent engineering and construction work. Alternatively, the owner could impose a requirement that the contractor accept the risk of any errors in such a survey, and thereby suggest that the contractor carry out supplementary surveys to satisfy itself as to survey results. If the owner is reasonably satisfied that the surveyor has carried out its work in a diligent and professional manner, it would be costly to prohibit the contractors from relying on such a survey, mainly due to the added expense of re-surveying that would invariably be added to the price of the work. The parties may well agree to various acknowledgments regarding the nature and content of those engineering studies or other information that the contractor may rely upon or otherwise assume as the basis for its price and contractual terms. Typically, the work that the owner has carried out to date. if it is a reasonable basis for submitting a bid on engineering. procurement, or construction, can be relied upon by the contractor, and the owner will accept the risk associated with its (or its agent's) work being substandard. One mitigation tool in respect of a contractor discovering that the owner has made an error, and the contractor choosing to carry on in the face of such an error, is to impose the requirement on the contractor to disclose immediately to the owner any apparent errors in the owner's work and, if the owner is particularly risk averse, to impose upon the contractor a requirement that it carry out certain work that has already been carried out by the owner. $\Lambda$ middle ground (in respect of these provisions) might be to provide the contractor with a period of due diligence after which the contractor will be deemed to have accepted any shortcomings of the owner's previously executed work.

\section{The Change. Order (OR "I Thought Wf HaI) এ DeAl. - WhY AM I PAYITG FOR EXTRAS?")}

Unlike many contracts, an EPC Contract typically provides a mechanism by which the parties actually contemplate amending the provisions of the contract from time to time. Utilization of these provisions. known as "change orders." may be frequent or relatively 
infrequent, depending on the nature of the contract, the degree of specificity of the work initially described in the EPC Contract, the basis for the contract price, and other factors. In any event, change orders can significantly change both the cost and schedule of projects so they should be anticipated and accounted for in the EPC Contract and the reporting systems prescribed.

Consideration must first be given to who may propose a change order. An owner usually retains the right to modify (by addition, deletion, or substitution) the scope of work, the contract schedule, or any other part of the contract. The contractor will then evaluate the cost of the modification and it will be for the owner to then decide whether to proceed to issue a change order, typically on the terms of the proposed modification and evaluation.

The circumstances under which a contractor may initiate a change order are typically more onerous. The owner will view such requests with some suspicion. In the majority of circumstances, the owner may suspect that it is being asked to pay "extra" for work that was already understood to be included in the EPC Contract. To minimize both the number and frequency of change orders, the EPC Contract will often provide that there must be an "event change" before application can be made or brought for a change order. While the definition of an event change may be the subject of some negotiation, it will typically be incumbent on the contractor to show an event (or events) has occurred giving rise to a material increase in the obligations of the contractor under the scope of work. Alternatively, a contractor may have to demonstrate that an event has had an adverse effect on the ability of the contractor to meet the project schedule. In either circumstance, the event: (a) must have occurred due to acts or omissions beyond the contractor's control; (b) could not have been reasonably foreseen by an experienced contractor; or (c) was not otherwise contemplated under the EPC Contract. All of these qualifications, and others, are used to limit the contractor's opportunity to obtain a change order.

Change orders are also common under longer running EPC Contracts to account for any changes in law coming into effect during the term of the contract.

In all cases, an evaluation of the change would be prepared by the contractor prior to the owner approving the request. Upon settlement of the change order, the EPC Contract price would typically be amended and change orders will cause corresponding adjustments to contract schedule, the contractor's work force plan, and other elements of the EPC Contract as applicable.

If parties are unable to reach agreements on adjustments necessitated by a change order, the owner will usually insist that the contractor proceed with the work and that the owner will establish adjustments (including the amount of compensation and any adjustments to the contract schedule). If all commercial efforts fail to provide agreement on the terms of the change order, the dispute may be resolved under the dispute resolution mechanism of the EPC Contract.

In some instances, utilization of the change order mechanism can be among the most contentious provisions of an EPC Contract. Under a lump sum contract, the change order is the instrument most commonly used by the contractor to press for price increases regarding: (i) any portion of the scope of work that the contractor or the owner misunderstood; or (ii) 
any costs that have been miscalculated. Conversely, the use of change orders may be discouraging to one or both parties if the reason for the change, and the corresponding delays or cost impacts, are the result of poorly drafted scope of work documents or an unworkable change order procedure. Perhaps the change order mechanism is best understood when a contractor is retained very early in the initiative, the development of the scope is more iterative, and both parties are expecting change orders in the normal course as the project develops, changes, and changes again.

Without a solid understanding of the change order provision and the circumstances in which it is to be followed, parties may: (i) put themselves through needless stress in coming up with a fair and equitable method of agreeing upon bona fide changes; or (ii) be exposed to risk, by skewing their agreement through a subsequent, non-compliant course of conduct. Indeed, it is common for parties to ignore the change order provisions of an EPC Contract in favour of an alternative arrangement that becomes so imbedded that it becomes unreasonable to impose the express change order process on the parties. The western Canadian cases of Kei-Ron Holdings Lid. v. Coquihalla Motor Im Lid." and Bamister. Pipeline Construction Co. v. TransCanada Pipelines LAd. ${ }^{\circ}$ are perhaps two of the clearesi examples of where the parties were well aware of the requirement for written change orders, yet chose to ignore these requirements. When the parties proceeded with changes based on verbal requests, they were forced to confront the uncertainty surrounding liability for the costs of performing extra work. It is at least arguable that this uncertainty would have been avoided if the parties had simply followed the change order provisions contained in the contract negotiated between them.

\section{Post Exlicution - OWNer Approval. and Notich.}

Following execution of the EPC Contract, it is inevitable that one of the parties will require further input, information, or direction from the other party. Throughout the duration of an EPC Contract the parties will exchange technical, logistical, or commercial information. Either party, depending on its interests, may insist on one of the following levels of participation regarding documents, instructions, or decisions: (a) notice; (b) notice with an opportunity to review and comment; or (c) the right to withhold approval of the proposed course of action. Examples of the type of material or information requiring owner notification include: (i) submission of design drawings to the owner; (ii) a proposed variation of certain engineering documents; (iii) notification to the owner that the contractor is ready to proceed with a new phase of the initiative; (iv) preparation of a procurement package or related contract to be let on behalf of the owner; (v) notice to the owner for review or approval of proposed subcontractors; ( vi) notice of delivery of certain goods to site; and (vii) preparation of pre-commissioning procedures.

In most commercial arrangements, obtaining a counterparty's approval for such matters as assignment of the agreement to an affiliate, amendment of the agreement. or a change in price does not imply that the party approving the matter is taking particular responsibility for the technical basis of the document or matter to be approved by the other party. For example. 
if the purchaser under a gas purchase agreement has been asked to approve the assignment of the agreement by the supplier to a supplier affiliate and that affiliate assignee (i.c., the new supplier) proves not to have the technical wherewithal, gas supply, transportation capacity, or creditworthiness to satisfy its gas delivery obligations, it would not typically be the case that the purchaser who approved the assignment would forfeit its claim to the gas and possible damages resulting from a breach of the gas purchase agreement (presumably because it "approved" of the assignee). In some cases under an EPC Contract regime, and particularly for engineers and design professionals, "approval" can mean that the approving party has satisfied itself as to the appropriateness of the decision and accepts the consequences of the approval. This could be the case for an owner who approves an order for structural steel that is found out many months later to be inadequate to support the applicable facility, because the nature of the approval could effectively bind the approving party.

Much of the case law dealing with approval for the purposes of EPC Contracts focuses on an owner's approval of completed work during an inspection or acceptance process. ${ }^{7}$ While there appears to be no Canadian case law on point, leading authorities give some guidance by indicating that "in the comparatively rare case where work is expressly to be done to the approval of the building owner ... the general rule in building cases was that the covenant to obtain approval overrode any other stipulation describing the work, and, once approval had been expressed, the building owner was liable for the whole price and was debarred from complaining of defective work."

\section{As H.M. Wise suggests:}

Often design/build contracts are drafted to afford the Owner the opportunily to have some input into the ultimale plant syslem which is provided. However, care should be taken in drafing such agreemems to 'nswe hat the Owner's involvement is not later taken to be treated as some how assuming some' responsibility for the design of the product which is whimately provided. The Owner may have valid questions, concerns, or input which may affect the ultimate design and result in alterations thereto. However. in all instances, these interactions should be limited so as to not usurp the role of the design builder in the process. For example, the Owner may have certain requirements for equipment compatibility or use which may result in alterations to the design builder's ultimate design. These may not become apparent until the design builder has provided the Owner with its design and has provided its detailed specifications and specified the equipment which it is planning to include in the project. The Owner should rake care that its input is timited, failing which, the design builder may assert a claim that the Owner interfered with the design and/or construction process of the design builder."

It is therefore in the owner's interest to have the EPC Contract contain a strong, explicit exclusion of owner liability flowing from the owner's approval of documents presented to

See Butemem (l.ord) v. Thompsom (1875). 2 Hudson's Building Contracts (4th ed.) 36 and Bruens v: Smith (1951). I S.A. 67, as cited in I.N. Duncan Wallace, Hudson's Building and Engineering Contrects, 1 lth ed., vol. 1 (London: Sweet \& Maxwell, 1995) at para. 5.012.

" Waltace, ibid. [emphasis added].

4 Howard M. Wise, "Risk Allocation — In Design/Build - The Owner's Perspective" (paper presented al the Construction Risk Management Conference, 25 November 1998)(Torontu: Federated Press, 1999) al 6 [ermphasis added]. 
the owner by the contractor. Typically the courts will enforce a clear, unambiguous exclusion clause, particularly when such a clause is negotiated between sophisticated, experienced commercial entities that have equal bargaining power. The courts will interpret such clauses strictly against the party seeking to enforce the clause.

In addition to the use of an exclusion clause, an owner should consider defining more precisely the purpose of the review or approval that the owner is providing. For example, an owner may only be interested in verifying that a document or design purports to meet the owner's requirements, such as the dimensions of the physical footprint, compatibility with other site operations, and activities or design factors relating to the safety, environmental, and emissions criteria. If the intention is that the construction, functionality, and integrity of the construction is to continue to be the responsibility of the contractor, then the express terms of the approval/review requirements should confirm this understanding and qualify the approval process accordingly.

If an owner intends to "approve" technical matters, and therefore duplicate such activities being carried out by the contractor under an EPC Contract, then the approval process need not be qualified. This duplication of activities would be costly and time-consuming, but could be reasonable in some circumstances.

\section{NOTICE (OR "WHAT DO You MEAN YOU HAD NO IDEA?")}

While notice provisions are typically understood as "boiler plate" in many types of commercial arrangements, the ongoing dialogue between parties to an EPC Contract regarding approval does require greater attention to detail. A multilude of individuals representing the contractor, the owner, and their agents will be exchanging documents. It may be prudent that the parties establish a formal framework for communication regarding a variety of engineering specifications, status reports, meeting minutes, audit reports, and other communication mechanisms. Such a framework should be able to address both parties' needs for timely, efficient, and definitive correspondence.

The form and content of notice that is viewed as appropriate will vary among individuals practicing in different disciplines. The nature of notice will likely be subject to modification during the life of the EPC Contract as well. Despite the specific wording of the notice terms and conditions, as the nature of the relationship among the parties changes, so too will the degree of compliance with, or enforcement of, the notice requirements. As tension or frustration increases, an innocent party will point to the black letter of the notice provisions: with success will come a relaxation of the strict terms of notice, often through conduct and not a formal amendment to the EPC Contract.

The information exchange by the parties should be transparent and readily available to the individuals who will require such information. For example, the engineering integration groups of the applicable parties must be able to access all relevant engineering details so that certain interface, quality, maintenance, and other requirements are veriliable and accounted for. Similarly, the parties' accounting group must be able to identify the status of invoices. possible "backcharge" or "set-off" items, and the background information supporting such invoices so that delays in the issuance of invoices, the rectification of any disputes regarding 
invoices, and the payment of invoices are dealt with as expeditiously as possible, thereby minimizing frustration and financing charges.

This significant and voluminous exchange of information can be complicated by the inconsistent application of the systems established, if indeed sufficient systems have been established. The exchange of information can be challenged further if the parties choose to dispute midway through a project the validity of certain notices, such as change order requests. Disputes over change orders may be indicative of more significant issues, such as a contractor trying to claw back certain costs not previously accounted for, but are often claimed on technical or legal grounds. It would not be unusual for a disputing party to question the validity of a change order, notice, or request based on the nature of the previous correspondence. Specifically, parties have been known to dispute that an email transmission between appropriately authorized personnel is not "written" notice for the purposes of the EPC Contract.

It is now generally settled that the courts view email correspondence as "written" correspondence unless the provisions of the EPC Contract specifically exclude the use of email correspondence in the applicable context. As an example of such an exclusion, an EPC Contract may provide that invoices are to be delivered by courier to a particular department in written form at the recipient party's office but no email address is provided. Unless other factors, such as a course of conduct of the parties ignoring such courier formalities in favour of a more expeditious email delivery, were in existence, then only a hard copy delivery of such invoice would be considered acceptable delivery. More typically though, the exchange of emails or other digital media have been recognized as valid, binding communication and parties should account for this in their coordination procedures.

\section{Breach OF CONTRact (OR "NOW THE Bad NewS")}

The relationship between the owner and the contractor is intended to be long term, and interdependent, and the parties expect that it will not be easily unwound. There is an entire spectrum of remedial measures available to an owner and a contractor in the event that the other party is not satisfying its obligations, and when the project itself still has numerous hurdles to cross before completion is achieved.

As is the case for parties to many forms of commercial agreement, a contractor will be considered to be in delault under an EPC Contract if certain events or conditions arise or exist and the contractor fails to satisfy such conditions within the particular curative period, if such a default is capable of being cured. Examples of defaults include:

(a) any material breach of a representation or warranty;

(b) a breach or default of a material requirement relating to safety;

(c) abandonment of the work;

(d) failure to maintain any required perlormance security or insurance;

(e) failure to pay any amounts due to the owner;

(f) material breach of any obligation under the contract;

(g) insolvency of the contractor; and

(h) inability of the contractor to achieve specific performance guarantees in respect of the work. 
If the contractor is indeed in default and the default has not been cured within the applicable curative period, the owner's possible remedies vary widely and the decision to exercise those remedies will depend largely on the owner's underlying concern, including ultimately whether the owner believes that the contractor can do the job.

While not exhaustive, an owner's remedies would typically include the ability to:

(a) suspend the contractor's performance of the work, in whole or in part and at the contractor's cost, until such time as the contractor has remedied the default or proposed remedial measures that have been approved by the owner;

(b) terminate the EPC Contract, enter the work site (or anywhere that the work is ongoing), and complete any outstanding work at the contractor's cost, including the hiring of other contractors;

(c) take immediate delivery of the work, in its then current state, and immediately assign from the contractor to the owner any subcontracts required by the owner in order to complete the work;

(d) take over from the contractor any part of the work and undertake the performance of such work at the contractor's cost;

(e) take over the contractor's property, particularly construction equipment, to use for the purpose of completing the work; and

(f) make appropriate demands for performance or payment under applicable performance security.

A cursory review of the above remedies would give the impression that significant intervention by the owner is typically the next step in response to a default, when in fact such a response is more likely to be a response of last resort. Utilization of any of the foregoing remedies requires some consideration of whether the owner's intervention will actually alleviate the perceived ongoing default. The owner must be confident that other contractors and sufficient labour are available to complete performance of the work in a timely, cost effective manner. If not, many of the aforementioned remedies will be nothing more than theoretical options.

The first sign that a contractor is experiencing difficulty is when it becomes clear that the contractor's work product is either delayed or of inferior quality. The EPC Contract will often provide that if the owner has determined that the contractor will not be able to achieve a material milestone or is delivering substandard work, then the contractor will be notified and required to submit a recovery plan for the owner's approval. If the recovery plan is approved, the contractor will be expected to implement that plan promptly. If it is not approved, the owner may direct the contractor to take any remedial steps specified by the owner. In either case, remedies might reasonably include: (i) the institution of overtime; (ii) an increase in the number of personnel at any level; (iii) an improvement of quantity or quality/capacity of equipment: or (iv) other actions reasonably required to achieve the required milestone or to get the project back on track. Unless some sort of intervening cause is at the root of the difficulty, the contractor should expect that the cost of implementing the remedial measures will be at the contractor's expense. Owners will have the expectation that a first rate EPC contractor will reallocate its resources to the owner's project and effectively get the "A-Team" on site once the owner has made it very clear to the contractor that the 
contractor is in breach of its obligations and that changes are expected to occur if more drastic action by the owner is to be avoided.

To be clear, the imposition of remedial steps by the owner should only occur after the owner has attempted other, less invasive means of getting the project back on schedule and within budget. A sophisticated owner would likely have its own resources, often embedded within the contractor's team. Initially by informal means, and later by the use of more formal notice mechanisms, the owner would likely prod the contractor to develop, or provide the contractor with, some suggested alternative approaches or "work-arounds" to achieve the desired results. Often it is sufficient if the contractor makes some changes in its team leadership or if one or more subcontractors or sub-suppliers are changed out, usually at some financial cost to both the contractor and owner. Intermediate remedies might include changes on the owner project team or the inclusion of third-party consultants and advisors to assist in improving progress and quality. While many of these initiatives might be imposed on the contractor at the contractor's cost, the better view is that, unless it can clearly be shown that the difficulty is entirely within the contractor's bailiwick, the owner will bear much of the burden for what might be considered "interim fixes." While the difficulty may appear to be within the contractor's scope of work, these rather major decisions (to change out leadership or subcontractors or bring in consultants) are usually of such significance and presumably of such net benefit to the project that the owner, who ultimately has the most to gain from a successful outcome, will be inclined to cover these sorts of additional costs.

At least two caveats applicable primarily to the owner should be noted at this point. First, any proposition put forth to the contractor should be understood more in terms of being a suggestion, or perhaps a warning, supposition, or a brain-storming of ideas. If the owner in effect starts directing the activities of the contractor, there is a very real risk that the contractor will be able to point to the owner as the cause of any delay or qualitative difficulties. Any such direction might well make it impossible for the owner to then rely on the EPC Contract as it relates to such basic terms as cost certainty, completion date commitments, and associated liabilities, including the availability of liquidated damages. Second, any interference by the owner with the execution of the work may well have an impact on any performance security provided under the EPC Contract. This includes, in particular, the enforceability of any performance guarantee and any performance bond that may have been provided.

A fundamental principle of the law of contract is the concept of "material breach"; whether circumstances are such that an innocent party would be entitled to repudiate a contract based on the contravention of a material term by a counterparty. Material breach is no less of a concem in an EPC Contract, even though the contract provides more obvious alternatives than contract termination. The EPC Contract will often specify at whose cost a certain activity will be undertaken. If otherwise silent on a given point, the appropriateness of a change order as a proposed solution will be raised by one or both parties. The implication is that in circumstances where a change order is appropriate, or specificity exists as to who will bear the cost of a particular activity, damages are understood to be an appropriate remedy and the breach is unlikely to be material. If either party insists that a particular event should give rise to contract termination then the draftsperson should make such provision clear and unequivocal. 
A typical feature of many EPC Contracts, particularly construction contracts, is the ability of the owner to take over any part of the work, including partially completed work, in respect of which the contractor is in default. It is rare that such a provision is acted upon and this provision has the appearance of an equity-like remedy. Enforceability of such a provision would likely be dependent on the circumstances of the contractor's default, but would more likely be utilized the closer the project is to completion when the default occurs. Under such a provision, the EPC Contract might provide the owner with the right to assume direction of and use construction equipment and property of any kind. including the contractor's intellectual property and premises. The owner would only be required to eompensate the contractor for such use if, after completing the "take-over work" and accounting for all the additional expenses borne by the owner and associated with completing such work, there was some credit owing to the contractor on the contract price.

The owner would be well advised to keep meticulous records of its costs and expenses associated with the completion of take-over work in the event that the owner felt it advantageous to proceed under such a provision.

While neither party truly wishes to contemplate the possibility, circumstances may sometimes change drastically and the prudent draftsman will want to contemplate both suspension of work and termination of the EPC Contract at the convenience of the owner. Unequivocal notice of suspension provisions should be included in the contract along with a provision permitting the conversion of suspension to termination by a party after a sufficient passage of time. Fairness will dictate that the contractor be permitted to submit a change order for reimbursement for any justified and satisfactorily documented expenses directly incurred as a result of such suspension. Reimbursement claims may include the cost of putting up, storing, and safeguarding partially completed work, construction equipment, and materials committed to workshops or on a project site.

Ultimately, if the EPC Contract is terminated at the owner's convenience, provision should be included for delivery of work (in whatever state of completion) and assignment of subcontract and supply agreements to the owner in exchange for which the owner would:

(a) pay the contractor a quantum corresponding to the percentage of work completed by the contractor (a mechanism being required to determine such percentage); and

(b) reimburse the contractor, upon presentation of supporting evidence, for costs incurred in expectation of completing the work, including costs of cancellation and settlement of claims arising out of the termination, the cost of equipment and materials ordered by contractor and for which the contractor is obliged to accept delivery, demobilization costs, and other reasonable direct costs incidental to contract termination.

The contractor, at law, has the obligation to mitigate reimbursable costs and this should be confirmed in the contract document.

\section{Limitations on LiamiLity (OR "How BAD CAN IT Grit?")}

The size and scope of some projects undertaken in the energy sector are massive and contractors are understandably reluctant to participate in EPC Contracts unless their risk is 
limited to a manageable degree. Parties recognize that, because the contractor does not participate in the consequential rewards that flow from the development of an operating project, the contractor should not be liable for the consequential losses flowing from an error or other event for which the contractor may be responsible that could result in the contractor's massive liability for a "legacy" project. In these circumstances, it is more typical that the risk be borne by the party in the best position to bear it, usually the owner.

Even the owner would probably agree that there is nothing to be gained by bankrupting the contractor. The contractor's liability would usually be backstopped by some combination of contractor and owner insurance, along with the assets of the contractor. The issue then becomes how any maximum liability might, or should, be determined and calculated.

Some contractors are of the view that their liability should not exceed some predetermined profit component that might be deemed to be included within its compensation for the scope of work. Agreement on such quantum would depend upon the transparency of the profit component within the contract price and the ability of the parties to agree upon what is included in "profit." For example, there may be animated discussion on whether any mark-up on subcontracts should be included in the calculation of profit or whether a calculation of overhead cost should be part of profit, especially when a calculation of paid overtime has been priced into such overheard.

Another, perhaps simpler approach, would be to calculate maximum liability as a percentage of the full contract price, although determination of what percentage may be the subject of heated debate. One advantage to this approach is that maximum liability will be reset automatically and in accordance with the provision of any change order that affects the contract price.

In EPC Contracts with very discrete packages of work, the use of "sub-caps" in the determination of maximum liability is not uncommon. For example, the parties might agree on a certain lower level of liability in respect of pure engineering work, a separate limit for procurement liability, and even different limits in respect of construction work, construction management, or supervision. Liability would still be subject to an overall maximum, but the utilization of "sub-caps" might well serve to lower the ultimate liability of the contractor.

One particular area in which liability is sometimes limited is in respect of the contractor's responsibility for repairs or replacement due to some defect in the work at first instance, typically a form of contractor breach of warranty. Sophisticated contractors will acknowledge that some degree of "re-work" will be necessary in the normal course and that large projects are unfortunately not exempt from such phenomena. The contractor will be anxious to negotiate for some sort of "stop loss" limitation mechanism for accessing and reviewing the defective item, often referred to as responsibility for "rip \& tear." Such a limitation could well include one or more of the following:

(a) rip \& tear having to exceed a certain quantum or percentage of a construction contract price, prior to which the contractor has no liability;

(b) liability being limited to the direct labour costs or a proportion of the direct labour costs for construction re-work; and

(c) a maximum (sub) cap for rip \& tear liability. 
Liability will, in all likelihood, also be limited pursuant to the indemnity scheme applicable to the particular project. Indemnity arrangements are often the most difficult arrangements that counterparties must settle before their agreement can be finalized. Clearly, liability arrangements must be congruent with the risk management scheme that the owner intends to have in place for the duration of the project. As a result, it must be acceptable to the project's insurers, and it must be adequately explained to and understood by the contractor, to ensure that the contractor, the contractor's risk management team. and the contractor's insurer are comfortable that pricing for the required risk management approach has been included in the contract price and that the required insurance will indeed be available and can be placed as necessary.

Indemnity arrangements are known to vary widely and there is tension between an owner's assurance that a contractor has sufficient financial exposure from its errors and responsibilities, and a contractor's assurance that the owner does not expect the contractor to insure the entire project. This tension is one that is not easily reconciled.

The most traditional approach has been the reliance on a negligence-based system. Liability for loss rests with the project owner, except to the extent that the contractor's negligence was responsible for the loss. Liability would flow from both negligent actions or inaction and omissions, and would typically extend to any wilful misconduct by the contractor or its subcontractors.

As suggested previously, liability would not normally extend to consequential losses. These losses typically include loss of production, losses of revenue, lost profits, lost opportunity, increased operating expenses, or exemplary or punitive damages, all of which may be considered risks that the owner is better able to manage and insure.

Arguably, there are circumstances in which contractors have been prepared to take on indemnity obligations in the absence of negligence. For example, "arising in any way out of, or in connection with, the performance, non-performance, or partial performance of an agreement" is a provision included in some EPC Contracts. A corresponding indemnity obligation on the part of the owner is conspicuously absent and the one-sidedness of the agreement is apparent. Such a provision, while perhaps enforceable, may be a somewhat dubious remedy on which to rely, as many contractors will not have the financial strength to survive, or otherwise insure against (if such an obligation is indeed insurable), such a substantial claim.

The alternative to a negligence-based approach is a "knock-for-knock" approach currently being used with increasing frequency. The essential elements of such an approach, with some marginal exception, provide that both the owner and the contractor:

(a) are solely liable for damages and losses to their own facilities, equipment, and personal property and injury to or death of their own personnel, even if such loss was caused by the negligence of the other;

(b) waive any recourse against the other for claims made by a third party for damages to third-party property and injury to or death of any third party; and

(c) in respect of the project itself (or perhaps more accurately, the assets that make up the project), are liable for and to the extent of loss as set out in the agreement. The 
contractor's liability would typically be limited to a negotiated sum and any liability in excess would be at the owner's risk.

The knock-for-knock approach is clearly intended to limit the slings and arrows associated with numerous liability claims and, so long as a provision is included that is similar to the foregoing listed in (c), it is likely that the counterparties would both have sufficient financial exposure to encourage high standards of conduct.

Attempt may also be made to limit liability on the basis of or to the extent that insurance responds to a particular claim. However, such an approach may be inappropriate, as it confuses the concept of liability with whether a tool for managing liability is effective. Nonetheless, such a limitation is not completely foreign to the EPC Contract. One difficulty with this approach is that the limitation is placed at least partly in the hands of a third-party insurer who may be motivated to deny the claim. The basis on which an insurer may deny coverage may have little to do with the agreement between the owner and the contractor. Further, it may be inappropriate to base an EPC contractual limitation on an insurance contract to which one of the owner or contractor is typically not a party. Another difliculty may arise when the insured has agreed to insurance policies with high deductibles, thus making the relevance of an insurance response dubious. This would be a common technique used by larger entities preferring only to insure against "the big one." It would not be uncommon to have many smaller claims well below the deductible limits, and in these circumstances, insurance response to a claim would be irrelevant. The foregoing would have similar application in the event that one or both of the owner and the contractor are selfinsured, making the availability and response of an insurer potentially self-interested and thus an inappropriate mechanism in respect of any limitation on liability.

\section{Sone Additional. Thoughts}

\section{A. Dispute Resolution (OR "Do I Have to Go TO MARRIAGe COUNSELling?")}

Much has been written about the desirability of alternative dispute resolution as a means of solving commercial disputes generally and construction disputes in particular. Discussion here will be restricted to how dispute resolution may differ slightly in the EPC industry.

Given the extended length of many "EPC marriages," representatives of both parties may become frustrated with the many and varied conflicts and irritations that tend to arise over the duration of the contract. One rather simple and quite effective means of managing a perceived dispute is to move it up the corporate ladder. More senior representatives of the parties, with the benefit of a longer range view and less personal investment in the dispute, may well be better positioned and more likely to have the corporate authority to resolve the dispute without having to obtain sign-off from more senior management.

It may be trite to suggest that time heals all wounds, but extended duration of work under an EPC Contract will indeed present many permutations and combinations of similar issues and problems. Many parties will find it sensible to maintain a log of ongoing disputes with counterparties, if only to ensure at the end of the process such disputes are ultimately dealt with and resolutions achieved. While some take the view that disputes be dealt with expeditiously, others are of the view that, with the passage of time, many matters will be 
sorted out on the job-site. This latter philosophy suggests that those representatives on-site will, on the basis of past experience and practice, better appreciate whether certain behaviours are truly aberrant and will determine how best to deal with them.

Another fairly common approach, perhaps adopted from labour law, would be a "work now - grieve later" strategy for dispute resolution. The parties might effectively provide by contract to set aside all disputes for a period of time up to the completion of all or a certain delineated portion of the work, and then attempt to settle collectively numerous outstanding matters on some sort of a global basis. While more commonly used in respect of construction contracts, there is no apparent reason that a similar strategy could not be taken in respect of a wider EPC dispute concerning compensation or timing. This strategy assumes the parties are continuing to act with bona ficles and neither party is being severely compromised or bankrupted by such conduct. Concepts such as "set-off," "respect in the industry," or "consideration of involvement on the next project" would figure prominently in such discussions and negotiations.

\section{B. Primf, Contractor}

The degree to which safety performance has come to influence positive work-site behaviours is a development long overdue and owner-contractor agreement on the importance of these behaviours is now a prerequisite to "getting everyone home safely."

Alberta's Occupational Heallh and Safety $A c t^{10}$ (the $A c t$ ) provides at s. 3 that:

Every work site must have a prime contractor...

(2) The prime contractor for a work site is:

(a) the contractor ... who enters into an agreenent with the owner of the work site to be the prime contractor, or

(b) if no agreement has been made ... the owner of the work site.

... the prime contractor shall ensure, as far as it is reasonably practicable to do so, that this Act and the regulations are complied with in respect of the work site.

... a prime contractor of a work site may mett the ubligation under subsection (3) ... [by doing] everything that is reasonably practicable to establish and maintain a system or process that will ensure conpliance with this $\mathrm{Act}$ and the regulations in respect of the work sile.

Prudence would dictate the need to confirm in the EPC Contract whether the owner or the contractor is taking on the role of prime contractor. If the owner is to take on the role, the EPC Contract should make reference to this fact and a covenant should be obtained from the contractor to the effect that the contractor will cooperate with the prime contractor so that the prime contractor may carry out its duties in accordance with the OIISA. 
If the contractor takes on the role, the owner might reasonably expect that the contractor will be obliged to provide significant resources for the task, that the subcontractors, other contractors, and the owner's own personnel are advised of this designation, and that all those entities are instructed to comply with the procedures and safety processes that are implemented on the work site by the contractor as the prime contractor.

Legislation now dictates that one person will be responsible for developing the on-site health and safety protocol and, in the absence of clarity on the issue, that person will be the owner. ${ }^{11}$

\section{Regulatory authorizations and Permitting}

The work prescribed under most EPC Contracts typically requires the concurrence of a variety of regulatory authorities. The contract should be clear as to which party will be responsible for obtaining the specifically identified authorizations, licences, and permits necessary to enable the contractor to carry out the work. The contract should then go further and clarify or stipulate who will be responsible for obtaining any authorizations, licences, and permits not specifically identified as being the responsibility of a particular party. Unless these matters are addressed in advance, confusion and change orders will inevitably arise.

\section{INTEllectual Property Rights — WHO OWNS THE "RESUI.T OF WORK"?}

There are competing views over who should own any intellectual property developed over the course of the engineering and other work under an EPC Contract.

The owner would argue that since it is paying the contractor for the work, any newly developed intellectual property should belong to the owner. The contractor would counter that it would usually be the case that the newly developed work product has simply been the result of further development of something that belonged to the contractor itself, a third party, or was available publicly. The contractor would also suggest that, in any event, all that the owner really requires is the ability to use that work product intellectual property for the useful life of the project. Ownership of this work product intellectual property may well be the subject of strenuous negotiation. However, if the owner is unlikely to benefit financially from the transfer or license of such rights to third parties, then it may be better to vest ownership of such intellectual property in the contractor, so long as the owner obtains an irrevocable, fully paid licence to use, modify, and improve upon such intellectual property for the useful life of the project.

A prudent draftsperson will need to understand those competing interests and, after determining that there are indeed new or improved intellectual property rights that may be deserving of protection, attempt to apportion those rights appropriately.

Any prior existing intellectual property being made available by a party must first be identified. This would include any rights that may have to be "licensed" by the owner. Any 
contractor intellectual property must be licensed by the contractor to the owner, including the right to modify and improve upon that contractor intellectual property.

In these circumstances, it would be common for the contractor to warrant to the owner that both the contractor's own intellectual property and that work product intellectual property developed by the contractor does not infringe any intellectual property rights of any third party. The contractor would typically agree to indemnify the owner if this warranty were untrue and the contractor would, in the face of such an adverse claim, be responsible for either: (a) procuring for the owner the right to the continued use of the infringing contractor or work product intellectual property; or (b) replacing or modifying the same to make the owner's use non-infringing while yielding substantially equivalent results at the same production cost to the owner.

\section{Conclusion}

An EPC Contract is arguably nothing more than a specialized form of commercial agreement. Whether as a stand-alone document or formed as a collection of numerous engineering, management, procurement, construction, and commissioning components, the EPC Contract is intended to document a "value add" that is ultimately greater than its constituent parts. For that reason, the effort required to accurately document the obligations of the parties requires the sophistication of any complex commercial arrangement.

The expectations of both the owner and the contractor for the EPC arrangement are inevitably high, and the risks undertaken by both partics may be exponential in relation to the expectation of profit or other "up-sides" that the parties believe that their enterprise should earn. For these reasons, a full understanding of the intended relationship, including the distribution of risk and skilful documentation describing that relationship, will be essential if the owner and the contractor are to find solace in their construction (marriage) document. 